\title{
Imagens e marcas: um imaginário ligado à epidemia de HIV-Aids no Brasil
}

\author{
Denise B. Portinari \\ Simone M. B. Medina Wolfgang
}

\section{Introdução}

\begin{abstract}
surgimento da Aids veio atrelado a uma reestruturação dos controles dos hábitos populacionais. Se a década de 1960 ficou marcada pelas fantasias de liberação sexual, a de 1980, graças à condução social da epidemia, inseriu-se em um contexto de controle absoluto e de uma suposta higienização dos hábitos sexuais. A manutenção do tratamento "simplista" aplicado pelos meios de comunicação no tocante à prevenção ao HIV e a repetição incessante dos discursos sobre o "sexo seguro" direcionam cada vez mais os processos de controle social ligados à epidemia.
\end{abstract}

Nenhuma doença provocou, nos últimos anos, tantas reações de angústia e fascínio como a Aids ${ }^{2}$, ao misturar os medos e os tabus milenares de epidemia, homossexualidade e morte. Suas vias de transmissão pelo sangue e pelo esperma são carregadas de ligação com as ideias de pureza, procriação e reprodução social (Pollak, 1990: 11).

A primeira resposta à epidemia por parte dos governos passou pela tentativa de se promover um controle dos hábitos sexuais, aliado à manutenção de uma sexualidade responsável/saudável, consolidando um modelo de prevenção e cuidado em saúde ligado ao HIV/Aids que promovia uma espécie de equação da moralidade na qual a castidade somada à monogamia e ao matrimônio resultavam na segurança e na certeza da soronegatividade. 
Aparentemente, a supressão da informação ligada às formas de contágio e a ênfase em aspectos mórbidos tiveram um grande destaque nas primeiras campanhas de prevenção, fomentando-se como paradigma fundamental do controle epidemiológico da Aids nos primeiros anos da epidemia. Foi nesse solo temático, que se desenvolveram os programas estatais de controle à doença e, por sua vez, as peças ligadas à prevenção, cuidado e manutenção relacionados às DST's, Aids e hepatites virais.

O principal objetivo desse artigo é promover uma reflexão sobre a formação de um imaginário imagético associado à Aids. Este foi sendo constituído, ao longo da história da epidemia com o apoio da linguagem utilizada pelos meios de comunicação, de forma a apresentar algumas consequências da formação desse imaginário para a condução social da epidemia na atualidade.

Começaremos abordando a construção social do problema e como a questão da Aids foi explorada pelos meios de comunicação, na primeira parte; em seguida pretendemos mostrar o tipo de ressonância que esse tratamento imagético promoveu no imaginário ligado ao HIV/Aids. Paralelamente, nos deteremos nas consequências práticas disso no tocante à condução social da epidemia, e finalmente apontaremos alternativas para o quadro atual, a partir de uma remodelação do conceito de prevenção ancorado nas premissas da RD (redução de danos).

\section{A construção do problema: a exploração da doença pelos meios de comunicação de massa nos primeiros anos da década de 1980}

A Aids surgiu no começo dos anos de 1980, e suas características epidemiológicas trouxeram consigo uma série de problemas sociais e morais, não apenas questões de ordem médica. A contaminação pelo sangue, esperma e as primeiras vítimas mais evidentes da doença - homossexuais masculinos e usuários de drogas injetáveis - reacenderam discussões de ordem moral que muitas vezes passavam ao largo do problema da doença em si e de sua grande capacidade de se alastrar. Alguns anos se passaram desde o surgimento dos primeiros casos até os reais esclarecimentos sobre quem estaria suscetível, as reais formas de contágio e como se prevenir de forma eficaz.

Entretanto, mesmo diante de uma ameaça potencialmente mortal, a questão moral parecia ser mais preponderante do que o perigo real representado pelo vírus. Naquele momento, meios de comunicação diversos (jornais, telejornais e revistas) divulgavam as primeiras imagens e informações vinculadas à Aids. O então crescente número de contaminações associadas a homossexuais masculinos forneceu munição para a criação de categorias de suscetibilidade ao vírus. Entre as primeiras causas levantadas para se explicar uma possível contaminação estavam a "vivência desregrada", os "estilos de vida alternativos" e a homossexualidade masculina. 
Um discurso sintetizado por parte da imprensa batizou a doença como "câncer gay". Imagens, em jornais e revistas, que retratavam as vítimas da doença, voluntária ou involuntariamente, como é o caso de diversas pessoas que foram fotografadas nos corredores dos hospitais nos anos de 1980, por revistas e jornais, no Brasil e no mundo não eram raras. Alguns exemplos podem ser vistos nas figuras 1 e 2 .

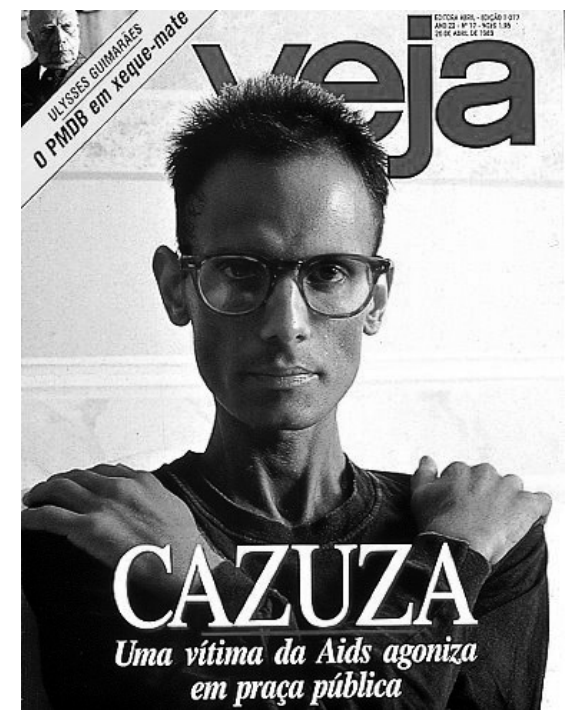

Figura 1 - Capa da revista VEJA de 1989

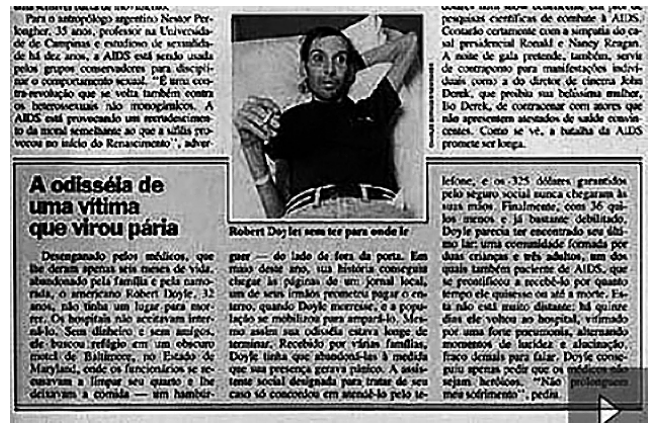

Figura 2 - Reportagem da revista VEJA de 1988

Esse tipo de conduta viria influenciar todo o tratamento discursivo e imagético ligado à Aids, criando estigmas e algumas vezes tornando a prevenção nebulosa, ou até literalmente equivocada. Entre os problemas derivados da divulgação desenfreada de informações imprecisas e errôneas estava também a apropriação do saber médico por pessoas leigas (mas com alguma ressonância entre certas camadas da sociedade), resultando na divulgação de um saber relacionado à Aids para o grande público, sem nenhuma informação médica fundamentada como respaldo.

A abordagem epidemiológica, classificando cada caso observado num grupo segundo fatores hipotéticos de risco, constrói os "grupos de risco" homossexual e toxicômano (...). A construção desses grupos age, portanto, pela observação de uma série limitada de casos, pelo isolamento das características comuns a esses casos, a saber: a homossexualidade masculina, o uso de droga por via intravenosa (...). A descoberta do vírus, o conhecimento cada vez mais apurado de suas vias de transmissão e a multiplicação de casos inclassificáveis questionam a legitimidade desse conceito (Pollak 1990: 123). 
Propagava-se à revelia informações equivocadas sobre risco de contágio, muitas vezes ignorando o que os pesquisadores já haviam descoberto na época. No final da década de 1980, o então, radialista Afanásio Jazadji, por exemplo, usava seu programa líder de audiência para promover suas próprias estratégias de prevenção. Em uma ocasião o locutor afirmou: "se você tomar um cafezinho no bar, numa xícara usada por eles (homossexuais), você irá contrair a doença” (Trevisan 2004: 442).

Esse conjunto de movimentos resultava no fomento da desinformação e do preconceito. Nos primeiros anos da epidemia, homens com práticas homossexuais foram tomados erroneamente como os grandes (ou talvez os únicos) vetores de propagação do vírus. De fato, muitos homossexuais vieram a se contaminar e a falecer por decorrência da contaminação pelo vírus da Aids e houve uma "super exploração" desse tipo de notícia por parte dos meios de comunicação em geral, promovendo uma série de reações dos setores mais conservadores da sociedade, que propunham todo tipo de "solução", desde a castração compulsória até o isolamento e encarceramento de homossexuais masculinos.

Infelizmente, a pseudo certeza que levava as autoridades a acreditarem que a Aids era uma doença restrita a grupos muito específicos foi a mesma que levou ao descaso com relação ao cuidado e à prevenção. A Aids era considerada distante e não prioritária, fazendo com que os investimentos em cuidados e pesquisa fossem deixados para segundo plano.

"Trata-se de uma doença preocupante, mas não prioritária", diz o ministro da saúde Carlos Sant'anna. De acordo com ele, os 6 milhões de portadores de doença de Chagas, os 8 milhões de pessoas acometidas pela esquistossomose e mesmo o 1 milhão de tuberculosos compõe um quadro muito mais assustador do que o da Aids (Veja, 14/05/1985).

A ausência de dados concretos com relação ao vírus, e suas primeiras vítimas mais evidentes, fez com que em muitas ocasiões o saber médico se focasse em aspectos sociais das vivências homossexuais masculinas, em detrimento dos possíveis aspectos físico-biológicos que poderiam resultar na contaminação pela doença. Foi dessa forma que a terminologia "grupo de risco" se incorporou definitivamente no discurso ligado à Aids, sustentando uma lógica na qual "quem você é" é mais relevante do "o que você faz".

O foco das suspeitas sobre os possíveis agentes de contaminação permaneceu durante muito tempo focado em aspectos da vivência homossexual masculina, em lugar de se investigar "o que" nos atos ligados a essa vivência poderiam a levar a uma possível contaminação. Infelizmente, somente após os primeiros casos relatados em crianças e mulheres casadas que haviam recebido transfusão de sangue, que o foco da atenção médica foi se modificando. 


\section{A divulgação da doença nos anos de 1980 e sua ressonância na atualidade}

Como vimos na seção anterior, na primeira metade dos anos de 1980, quando o vírus HIV se disseminou, o tratamento dado às informações ligadas à doença ressaltavam de maneira muito marcante o seu caráter fatal. Nesse cenário, slogans como "quem vê cara não vê Aids" ou ainda "se você não se cuidar a Aids vai te pegar", figuravam nos discursos habituais das campanhas de prevenção governamental até o começo dos anos de 1990.

Desde o surgimento da epidemia de HIV/Aids há quase quatro décadas, as imagens utilizadas para a representação midiática da doença foram aos poucos se modificando. A associação da doença a morte e a morbidez e aos "grupos de risco", foi, gradualmente, se dissipando e dando lugar ao discurso do sexo seguro e da sexualidade responsável, através do uso da camisinha.

Todavia, de alguma maneira, ainda há uma persistência das primeiras figuras associadas ao HIV - que carregam conotações muito estreitas com a morbidez, ou mortalidade eminente e a segmentação da doença por "grupos de risco".

Um exemplo prático disso é a forma como o tema ainda é abordado por alguns veículos de comunicação. Há alguns anos, em 2010, foi ao ar o programa Conexão Repórter, intitulado: "os filhos da Aids". O foco do documentário estava claramente ligado a aspectos relacionados ao mórbido, aos pacientes terminais, a uma rotina dura associada à medicação e ao abandono por parte da família do soropositivo. A comparação entre as imagens do programa a prevenção da segunda metade da década de 1980 é inevitável.

A característica mais marcante, no tocante à forma como a informação acerca da Aids foi tratada no programa citado, é a persistência da veiculação de um tipo de imagem associado à epidemia que não parece ter nenhum objetivo a não ser o da manutenção do sensacionalismo mórbido. Tal postura prejudica o encadeamento da prevenção, ao insistir no elo Aids e imagem do mórbido, reafirmando uma representação estigmatizante da doença.

A fala a seguir ilustra uma cena do programa, na qual o foco era uma jovem, extremamente debilitada, alimentada por tubos e semiconsciente deitada junto a familiares em um leito hospitalar de um centro de saúde para tratamento de HIV/ Aids em São Paulo.

Uma imagem emblemática: uma jovem em estado terminal. Renata, trinta e nove anos e trinta quilos. Ela não fala, não se mexe e só se alimenta através de uma sonda. Contraiu o HIV em 1986, durante uma relação sexual com o namorado. Mas Renata nunca se preocupou com a doença. A situação complicou há um ano e meio, quando ela parou de tomar os remédios. Teve tuberculose e contraiu um vírus que atrofiou o cérebro (SBT Repórter, 05/2010). 
Além da narração descrita (que conta com termos que estão para além que qualquer aspecto técnico ligado à ciência médica como "atrofia de cérebro"), outras imagens associando a Aids ao mórbido também foram exploradas como, por exemplo, a apresentação de uma "colônia para aidéticos" onde pessoas que sofreram algum tipo de rejeição pela família, e/ou que não tinham condições de trabalhar e se sustentar viviam graças a doações.

O programa SBT Repórter é apenas um exemplo de como a influência do tratamento que os meios de comunicação deram a questão do HIV/Aids no começo da década de 1980 foi preponderante para a formação de um imaginário ligado à doença que ainda permanece presente. Esse tipo de abordagem ainda encontra ressonância entre a população, perpetuando a estigmatização e indo de encontro a uma prevenção mais informativa e esclarecedora.

Um exemplo mais recente sobre o tratamento que os meios de comunicação de massa insistem em dar para a questão do HIV/Aids foi a reportagem "clube do carimbo", exibida pelo programa Fantástico no dia 15/03/2015, com a chamada: "Fantástico revela detalhes do 'clube do carimbo", abordando a rotina de homossexuais masculinos que supostamente transmitem o vírus HIV propositalmente. Apesar do infectologista do Hospital Emílio Ribas, referência no tratamento do HIV no país, Dr. Jean Gorinchteyn, afirmar que dificilmente alguém poderia estar agindo dessa forma, pois "a maior parte dos pacientes portadores de HIV são extremamente conscientes e preservam não só a saúde própria como dos próximos" (Fantástico, 2015), a reportagem abriu um pequeno espaço para a declaração do médico e se focou na apresentação de pelo menos 15 minutos de entrevistas com supostos "carimbadores" e histórias de pessoas que se contaminaram em relações sexuais desprotegidas, todos homossexuais masculinos.

A exploração do mórbido, a supressão da informação de prevenção, a insistência na questão dos grupos de risco e uma adoção de um paradigma de prevenção calcado quase que exclusivamente no discurso do sexo seguro nas peças de comunicação e prevenção à Aids suprimiram uma posição que deveria ser de retorno e diálogo. Com isso, acabaram por constituir uma espécie de "rede de equívocos" que ressona de maneira marcante na forma como as pessoas percebem a Aids, levando a uma má gestão da saúde individual no tocante ao HIV e outras DST'S.

\section{Algumas consequências práticas na condução social da epidemia de HIVIAids que derivam da abordagem social e midiática da doença nos meios de comunicação}

Mesmo com o passar do tempo, ao contrário do que se poderia supor, a descoberta e o isolamento do vírus e o conhecimento das reais formas de contaminação não subtraiu da literatura médica as condutas individuais de certos grupos sociais como um dos supostos vetores da transmissão do vírus. 
Algumas situações da vida cotidiana apontam que de certa forma a estigmatização ligada às primeiras vítimas da doença, relacionando risco e homossexualidade perdura até a atualidade. Um exemplo disso é a restrição imposta a homossexuais masculinos em território brasileiro, com relação à doação de sangue. A ANVISA através da norma $\mathrm{n}^{\circ} 153$ de 14 de junho de 2004 estabelece que homens que declaradamente mantiveram relações sexuais com pessoas do mesmo sexo, nos últimos 12 meses, não podem doar sangue.

Uma matéria publicada no jornal de Brasília de 14 de setembro de 2007 descreve o que ocorreu com o garçom Marcos Araújo, então com 32 anos que tentou doar sangue no Hemocentro de Brasília e foi impedido por ter se declarado homossexual. A restrição se manteve mesmo após afirmar que faz exames periodicamente e que não é portador do vírus HIV.

A decisão do banco de sangue tem dois apoios, as normas jurídicas - neste caso a legislação da ANVISA - e o saber biomédico, uma vez que a médica Anna Esther, do Hemocentro, justificou a persistência na proibição afirmando que:

Há um período em que determinadas doenças não são identificadas em exames, mas podem contaminar um receptor mesmo assim. Esse período é chamado de janela imunológica e a triagem clínica é um modo de reduzir ao mínimo o risco de contaminação. A pessoa que vai receber o sangue está debilitada, muitas vezes com o sistema imunológico fragilizado, então temos que garantir a segurança do material (Jornal de Brasília, 14/9/2007).

A fala da médica traz um questionamento interessante. É sabido que qualquer ser humano que tenha tido algum tipo de contato com o vírus pode estar em "janela imunológica" . Por que então essa proibição se restringe apenas aos homossexuais masculinos? Segundo essa lógica, qualquer pessoa sexualmente ativa estaria incapacitada enquanto doador de sangue. Todavia, pela legislação da ANVISA, apenas os homossexuais masculinos estariam sujeitos à contaminação, uma vez que "há um período em que determinadas doenças não são identificadas (...) e a triagem clínica é um modo de reduzir ao mínimo o risco de contaminação". Se a questão é o contato sexual de risco, a limitação quanto à doação deveria atingir todas as pessoas que fizeram sexo sem proteção nos últimos 12 meses, homens ou mulheres.

Apesar da medida descrita acima, o Brasil possuí um índice razoavelmente alto de contaminação pelo HIV por transfusão sanguínea, como mostra a reportagem da revista ISTOÉ de fevereiro de 2011:

Um em cada 100 mil bolsas de sangue do País pode estar contaminada pelo vírus causador da Aids. Nos EUA, a relação é de 1 para cada 2 milhões de 
bolsas (...) com números atuais, entre 30 e 60 pessoas por ano podem ser contaminadas por sangue doado. Os reflexos dos exames "falso negativo" podem ser constatados nas estatísticas. Dados do Ministério da Saúde mostram que 13,3\% dos casos da doença confirmados em 2009 foram causados pela transfusão de sangue (Rocha, 2011).

Todo esse aparato discursivo em torno da culpabilidade do homossexual no que diz respeito à doença desfoca de maneira demasiada os olhares para questões menos relevantes do ponto de vista médico/preventivo.

Apesar da permanência do modelo etiológico biomédico, o modelo etiológico social e psicológico continua a influenciar ainda hoje os trabalhos sobre o desencadeamento da doença, favorecido segundo alguns pela ação de cofatores que podem ser de ordem "não biológica"(...) Tal confusão criou então em muitos homossexuais o sentimento de que eram denunciados menos pelo que faziam do que pelo que eram. Daí as reações de contra denúncia, de desmentido ou... de temporização cautelosa (Pollak, 1990: 12).

Dessa maneira, aos poucos, a Aids foi se inserindo no hall das doenças "culpabilizantes" gerando uma série de metáforas ligadas à doença que na verdade só deslocam o foco da prevenção. A Aids é tida como obscena, fruto de uma vivência fora dos padrões, seja pelo uso de drogas, ou pela vivência de homossexualidade.

Como era previsível, em se tratando de uma doença ainda não inteiramente conhecida, além de extremamente resistente a tratamentos, o advento desta nova e terrível doença - nova ao menos enquanto epidemia - proporcionou uma excelente oportunidade para a metaforização da moléstia (Sontag, 2002: 76).

Em resumo, salvo prova em contrário, o doente de Aids é culpado pela sua doença. Se diante da fatalidade do câncer as pessoas sadias sentem pena, diante da Aids elas tendem a sentir raiva, a partir de um julgamento moral que a vê como doença do corpo resultante de uma alma conspurcada. Cria-se então uma mitologia que, infelizmente tende a se cristalizar em forma de arquétipo coletivo: a Aids é obscena. A partir daí, a doença fica sujeita às mais diversas formas de manipulação (Trevisan, 2004: 436).

Uma vez evidenciadas as "verdades epidemiológicas" sobre o vírus surgiriam então novas necessidades ligadas à gestão da saúde individual. Porém, no momento em que foi exposto o caráter universal da doença, o medo, os estigmas e as inverdades propagadas eram tantas, que prevaleciam mais as dúvidas e questionamentos, do que os fatos em si. Nas seções anteriores, mostramos como os 
primeiros ensaios de prevenção privilegiavam basicamente a questão do risco, seja de morte, de contágio, ou de exposição, em detrimento dos procedimentos a serem adotados para minimizar o contágio. Em um segundo momento a questão das mensagens de sexo seguro dariam o tom da prevenção, se tornando "carro chefe" da prevenção estatal brasileira.

Mesmo o saber médico como sinaliza Pollak (1990), estaria demasiadamente saturado de estigmas para lidar de forma objetiva com seu mais novo desafio. Parece haver uma superposição entre as variáveis sociais da doença e os dados epidemiológicos, o que tornou difícil a dissociação entre sintomas. Este fator, de certa maneira, sinalizou uma sociedade pouco preparada para lidar com ameaças inusitadas, como é o caso deste vírus que destrói algo que nos é organicamente muito precioso: a capacidade do nosso sistema imunológico de comunicar ao organismo que alguma coisa está errada para que possamos reagir.

A forma como a sociedade recebeu e reagiu ao HIV foi fundamental para que o vírus encontrasse o meio mais propício para sua propagação; a desinformação. Os riscos envolvidos na manipulação da informação e nos cuidados com o outro, viriam a se mostrar muito mais traiçoeiros do que se poderia de fato imaginar.

\section{As escolhas dos meios de comunicação no tocante à divulgação de notícias ligadas à doença nos anos de 1990 e 2000 e algumas questões importantes sobre essas escolhas}

Com base nos argumentos utilizados nas seções anteriores, pode-se dizer que duas vertentes marcaram a condução social da epidemia de HIV/Aids nos meios de comunicação. Em um primeiro momento, houve a divulgação ampla de informações tendenciosas ligadas ao caráter mortal da doença e uma suposta circunscrição do contágio aos ditos grupos de risco. O que se seguiu a esse "primeiro impacto" causado pela epidemia foi uma gradual mudança de foco e uma aposta na ênfase em uma prevenção que tinha como alvo a utilização da camisinha, e os discursos ligados ao sexo seguro. Esse, por sua vez, baseando-se na adoção em larga escala ao preservativo.

Apesar de uma amenização dos discursos em comparação àqueles divulgados nos primeiros anos da epidemia, a limitação ao discurso do sexo seguro ou à adoção de qualquer tipo de linguagem restritiva na prevenção não só oculta as formas mais eficazes de proteção, como perpetua os estigmas e a desinformação, resultando em um controle deficitário da epidemia.

Aliado a isso, o surgimento da terapia medicamentosa, no final dos anos de 1990, fomentou uma falsa ilusão de saúde e controle do HIV a partir da utilização dos remédios. Muitos governos (inclusive o brasileiro) passaram a apostar uma parcela generosa de seus investimentos para o combate à Aids, em fabricação e fornecimento de medicação, colocando a prevenção informativa em segundo plano. 
Os meios de comunicação de massa seguiram essa tendência e passaram a noticiar cotidianamente os avanços da medicação anti-Aids no final da década de $1990 \mathrm{e}$ no começo dos anos 2000, chamadas jornalísticas e manchetes de reportagens como: "Um novo coquetel de drogas anuncia o fim da Aids" (Alcântara, 1996: 88-93), "Aids a 1\% da cura", (Oliveira, 1996: 65-69), ou ainda "A cura da Aids?" (Santi, Gattoni e Vita, 2000: 44-47), eram bastante corriqueiras em jornais e revistas de grande circulação.

Contudo, sobre a realidade de quem se medica para viver com o HIV, é importante ressaltar que, apesar de algumas pessoas responderem muito bem à medicação, outras sofrem com efeitos colaterais pesados, e mesmo com a medicação, aproximadamente 12 mil pessoas morrem de complicações relacionadas à Aids no país todos os anos. "Em 2012, foram no mínimo 11 mil mortes, ante 18 mil em 2001 - mas o País ainda falha muito nas ações de prevenção" (Leite, 2013: 11-12) Apesar de existir tratamento, ainda não existe uma cura e, nesse cenário, a prevenção tem um papel fundamental.

Além disso, é importante ressaltar que os custos emocionais e financeiros envolvidos na convivência com o vírus são altos. Mesmo com o possível controle do avanço da doença através dos medicamentos, a adesão de forma regular ao tratamento não é fácil devido ao controle rígido necessário exigido pela terapia farmacológica. Outros dois aspectos fundamentais dizem respeito à rotina de exames trimestrais e acompanhamento médico para a prevenção de possíveis efeitos colaterais se fazem necessários.

Infelizmente, o direcionamento tomado pelos programas de prevenção não apresenta mudanças no sentido de se propor um diálogo entre os profissionais de saúde e a população. A maior parte das medidas é bastante prescritiva e unilateral.

Quanto aos meios de comunicação, no tocante à exploração de aspectos sociais e preventivos ligados à Aids, pode-se notar uma espécie de compartimentalização binária do discurso ligado ao HIV. Por um lado, fala-se na medicação e seus sucessos - sempre suprimindo os problemas, como os efeitos colaterais, por exemplo. Por outro, quando a notícia escapa a alguma novidade médico-farmacêutica, em uma divulgação ou outra, se fala em morte, doença ou grupos de risco de maneira mais esporádica, porém, persistindo em uma imagem da Aids dos primeiros anos da epidemia, como nos exemplos citados nas seções anteriores.

\section{Possíveis alternativas ao quadro atual}

No Brasil, em 2016, as políticas de tratamento e cuidados aos soropositivos estão entre as melhores do mundo. Existem centros de distribuição de remédios gratuitos, de apoio e testagem diversas, centros de pesquisa de ponta como a FIOCRUZ no Rio de Janeiro e o hospital Emílio Ribas em São Paulo, ONGs e grupos de apoio presenciais e virtuais que visam ao bem estar de quem convive com o vírus, seus parceiros, amigos e familiares. 
No tocante à prevenção, entretanto, ainda há lacunas. Algumas são mais evidentes e continuam aparecendo, com algum destaque, nos meios de comunicação. Um exemplo que ilustra bem a percepção equivocada que uma parcela da população brasileira tem com relação às formas de prevenção ao HIV são os resultados de uma pesquisa conduzida pelo Ministério da Saúde, em 2012, sobre Aids e possíveis formas de contaminação. Essas informações foram ao ar no programa Fantástico de $14 / 04 / 2013$.

96\% dos brasileiros sabem que se pega Aids fazendo sexo.

$90 \%$ dos brasileiros sabem que usando a camisinha se evita a Aids.

$56 \%$ dos brasileiros não comprariam verduras de um verdureiro conhecidamente HIV+" (Funcionária do Ministério da Saúde comentando sobre um questionário respondido por três milhões de brasileiros sobre Aids e educação, mostrado no Programa Fantástico da TV Globo no dia 14-04-2013).

O resultado dessa pesquisa mostra que os questionamentos ligados ao HIV/ Aids, feitos pelo cidadão brasileiro comum estão relacionados a aspectos muito básicos sobre a doença, como as formas de contágio. Apesar de boa parte dos entrevistados compreender que se pega Aids no ato sexual e que a prevenção se dá através do uso do preservativo, mais da metade dos entrevistados se mostrou desinformada ao temer a contaminação no momento do contato comercial de troca de mercadorias com um comerciante. No momento em que o contato esporádico com um verdureiro é tomado como situação de risco, a falta de informações pontuais sobre cuidados básicos de prevenção fica evidente.

Nesse contexto de equívocos e desinformações, é fundamental pensar em outras saídas para o problema da prevenção e da divulgação das informações sobre HIV/Aids pelos grandes meios de comunicação. A forma como ela é trabalhada atualmente é igualmente inócua, (no caso das mensagens de safer sex) ou até mesmo problemática. Quando uma propaganda do governo aponta para os remédios e a testagem como soluções absolutas para todos os problemas do soropositivo ela alimenta a fantasia de que os remédios proporcionam uma vida saudável e plena com o HIV.

Então, como podemos pensar em uma prevenção mais abrangente, que abarque o maior número de demandas relacionadas à prevenção ao HIV, de maneira a informar melhor a população e melhorar a resposta preventiva de maneira geral. Sobre isso Perlongher comenta:

Seria preciso, talvez, conceber uma política sexual diferente, que não desconhecesse a multiplicidade dos desejos eróticos nem tentasse disciplinar pedagogicamente os perversos e seus prazeres. Trata-se de oferecer a melhor informação possível, mas afirmando simultaneamente o direito de dispor do próprio corpo e da própria vida, já demandado por Engels (Perlongher, 1987 (a): 91). 
Levar em conta as subjetividades, os desejos, as diferentes demandas sociais/ culturais é um passo fundamental no sentido de se estabelecer diretrizes minimamente eficazes ligadas não só à Aids mas a outros grandes problemas de saúde de uma maneira geral.

Em seguida apresentamos alguns exemplos relativamente recentes de campanhas governamentais de cuidados e prevenção à Aids no Brasil. Como pode-se ver, o foco recai sobre a testagem, como na (figura 3) ou o uso de preservativos, (figura 4.)

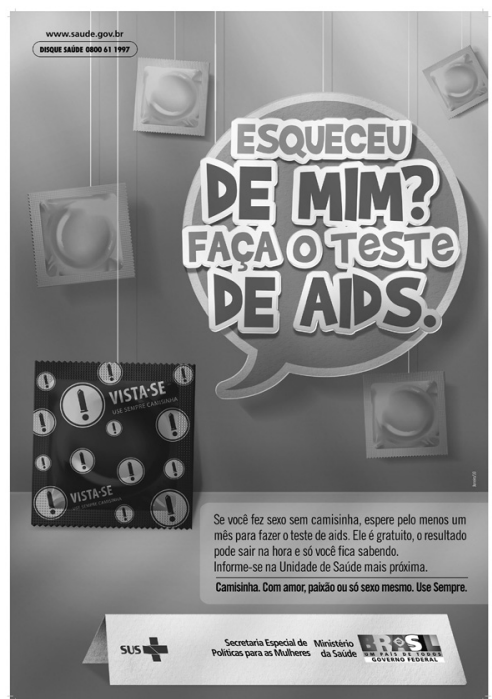

Figura 3 - Campanha para testagem 2009.

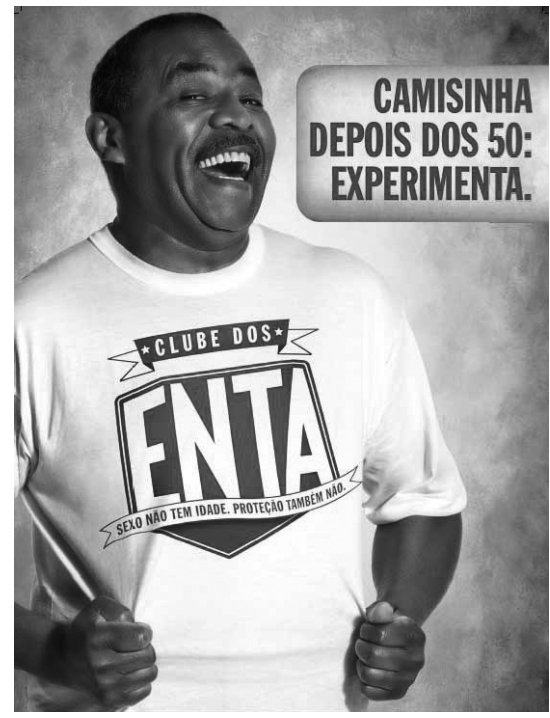

Figura 4 - Campanha carnaval 2010.

Uma possível saída para preencher as lacunas da prevenção no Brasil é apostar em campanhas informativas com um viés focado no diálogo, no questionamento e na interação contínua com a população. Iniciativas como essas já são utilizadas com sucesso em outras partes do mundo como Europa e Estados Unidos.

A prevenção nessas localidades se dá através de uma parceria entre público e privado trabalhando no tratamento e no aconselhamento da população de uma maneira muito abrangente e com constante trabalho em campo. A panfletagem e a fixação de cartazes ocorrem dentro de boates e bares de forma continua, assim como a distribuição de preservativos em locais como saunas e festas de sexo. Além disso, palestras e grupos de discussão são uma realidade cotidiana, com ampla divulgação e ressonância.

O formato da prevenção utilizada em alguns países da Europa e nos Estados Unidos possibilita o questionamento e, em alguns casos, abre um canal para o esclarecimento de dúvidas por parte da população. Alguns exemplos de campanhas que seguem esse eixo temático podem ser vistas nas figuras 5 e 6 . A série de campanhas intitulada Bathroom Ads ou "anúncios de banheiro", foi uma iniciativa 
da San Francisco Aids Foundation, no final da década de 1990, com o objetivo de informar populações jovens e/ou homossexuais masculinos sobre práticas sexuais menos arriscadas e medidas a serem tomadas em situações de risco. O slogan era think ahead, planeje-se antecipadamente.

Os anúncios possuíam chamadas como "sexo oral é sexo mais seguro", "o que fazer se a camisinha estourar" ou ainda "usa crystal?" seguido de uma série de tópicos objetivos, esclarecendo a conduta mais segura relacionada a uma dessas situações. Esses anúncios ficavam em banheiros de boates, saunas e locais voltados para a prática de prostituição. Já a (figura 7) é parte de um folheto distribuído pela ONG inglesa GMFA, e possui informações muito detalhadas sobre sexo, sexualidade, contaminação pelo HIV, diálogo com o parceiro, sexo com e sem preservativo, o que fazer para tornar a relação mais segura. Trata-se, portanto, de uma compilação de informações muito completa sobre saúde sexual voltada para homossexuais masculinos. Esse folheto é distribuído na sede da ONG, em bares e sex shops e possui versão on-line para consulta e download. Esse tipo de iniciativa, calcada na redução de danos ${ }^{5}$ ou RD, é uma alternativa às políticas públicas atuais, pois ela relativiza algumas questões acerca da prevenção, podendo abarcar uma parcela mais significativa da população, já que ela leva em conta situações de cunho subjetivo em detrimento da exclusividade das prescrições de sexo seguro.

O objetivo das ações de RD é preparar o indivíduo para lidar com eventuais situações de risco. As ações de RD devem preconizar, se possível, a redução de todos os danos à saúde dos indivíduos, em qualquer tipo de prática que possa ser lesiva ou daninha ao organismo. A RD considera em suas ações questões estruturais e culturais desenvolvendo programas que coloquem em ação estratégias de proteção, cuidado e autocuidado, procurando uma mudança de atitude frente a situações de vulnerabilidade.

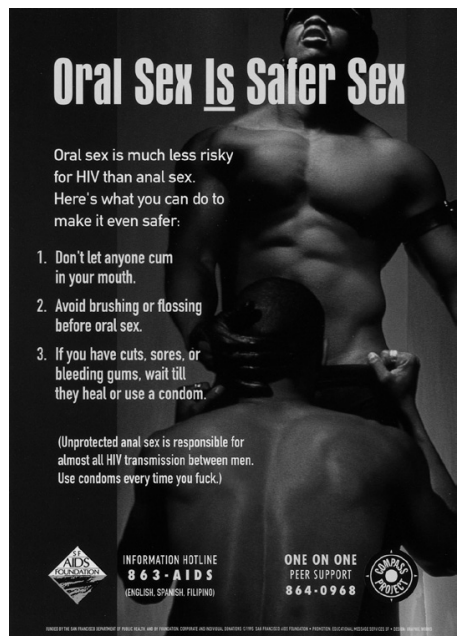

Figura 5- Sexo oral é sexo mais seguro.

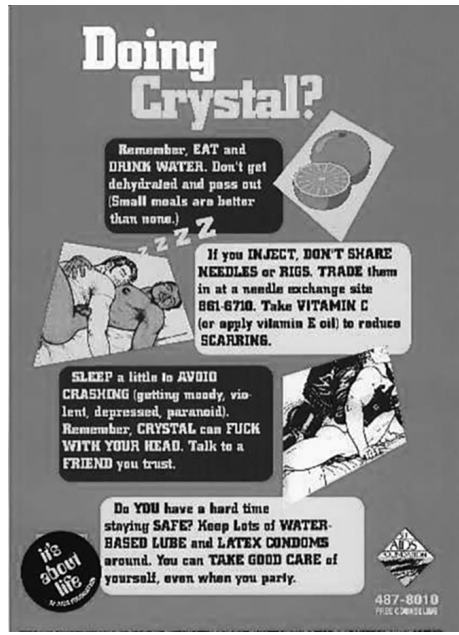

Figura 6 - Usa Crystal? 


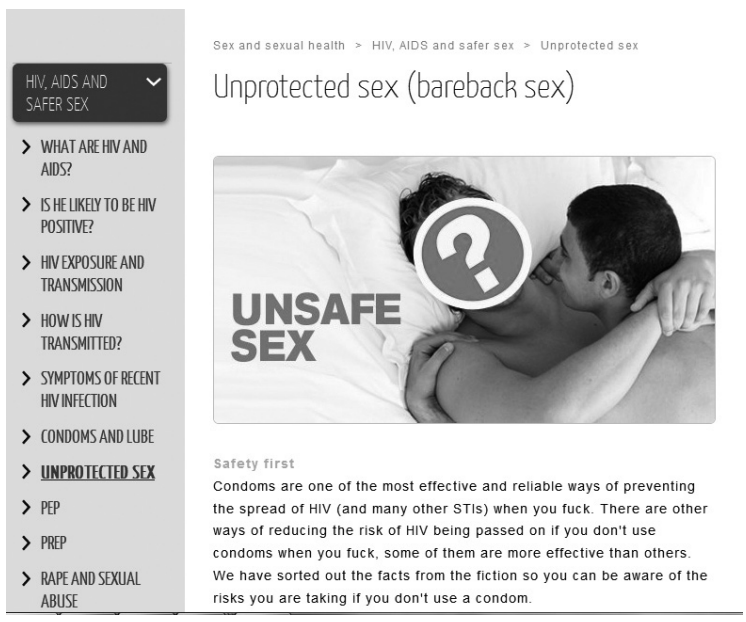

Figura 7 - Detalhe de folheto explicativo da ONG inglesa GMFA.

\section{Conclusão}

Ancorar a prevenção brasileira em aspectos ligados à redução de danos, assim como a ampliação do volume de informações epidemiológicas e de prevenção, disponíveis à população a partir da divulgação de notícias por parte dos grandes meios de comunicação é um ponto de partida para se pensar alternativas a prevenção atual. Deve-se ter em mente que as necessidades de prevenção diferem de país para país. Todavia, a partir de um levantamento de dados detalhado, pode-se pensar na adaptação desse modelo, ou de algumas partes dele, para a realidade brasileira mantendo a sua essência, que é o questionamento de dúvidas e a divulgação de informações da maneira mais abrangente o possível.

Nesse contexto, a criação de equipes multidisciplinares de profissionais das ciências humanas trabalhando em conjunto com profissionais da área médica em todas as etapas da elaboração da prevenção poderiam, possivelmente, adaptar o programa brasileiro à realidade e às demandas do século XXI, de forma a melhorar a qualidade de vida de diferentes populações.

Denise B. Portinari

Professora da Pontifícia Universidade Católica do Rio de Janeiro (PUC-Rio)

Simone M. B. Medina Wolfgang

Professora do Centro Universitário Carioca (UNICARIOCA)

Recebido em novembro de 2016.

Aceito em fecereiro de 2017. 


\section{Notas}

1. A grafia do termo Aids será utilizada neste artigo somente com a primeira letra em maiúsculo. Essa opção se deu pela demanda do movimento social de pessoas vivendo com o vírus que acredita que a mudança gramatical desloca o foco da patologia para a pessoa vivendo com a síndrome. A nova terminologia foi adotada inclusive pelo Ministério da Saúde.

2. Fizemos uma procura por definições de sexo seguro tanto na internet quanto na literatura voltada à prevenção a Aids e encontramos informações muito diversas. Se tomarmos o Ministério da Saúde como referência oficial nos cuidados em saúde para a população em geral, sexo seguro é uma atividade sexual em que ambas as partes estão engajadas no sentido de tomar precauções contra doenças sexualmente transmissíveis (DST's) como, por exemplo, a Aids. Já o sexo inseguro, ou sem camisinha é uma atividade sexual sem precauções.

3. Nomenclatura utilizada pelo locutor do programa, tendo em vista que o termo aidético adquiriu uma conotação tão negativa que não é mais utilizado pela maioria dos meios de comunicação que fazem referência ao paciente infectado como soropositivo, ou até portador. O termo é muito malvisto pelos ativistas dos direitos dos doentes e pelos próprios soropositivos.

4. Janela imunológica é o período entre a contaminação pelo vírus e a sua detecção pelos exames de sangue, o que pode ocorrer entre um e seis meses após o contágio. 5. A Redução de Danos é uma política pública que tem como objetivo principal reduzir os males decorrentes de práticas consideradas daninhas ou que tragam algum risco à saúde, como o uso abusivo de drogas, bebidas alcoólicas, a prática de sexo desprotegido entre outras. A Redução de Danos ou (RD) no Brasil é uma política pública autorizada e utilizada pelo Ministério da Saúde e atualmente é a prática prioritária para o desenvolvimento de ações junto a usuários de drogas que são desenvolvidas pelas três esferas de governo e também por organizações da sociedade civil.

\section{Referências}

ALCANTARA, Eurípedes. Enfim a esperança. Revista VEJA, n. 452, 19/07/1996 - Artigo de revista.

CALCAGNO, Luis. Polêmica: impedido de doar sangue. Jornal de Brasília, Brasília 06 set. 2007. FOUCAULT, Michel. História da sexualidade volume I. Rio de Janeiro: Graal 2005.

LEMOS, João Francisco de. O risco em cena: análise das campanhas de prevenção à AIDS da MTV Brasil. Dissertação de mestrado. Instituto de Medicina Social. Ciências Humanas e Saúde UERJ, Rio de Janeiro, 2006.

LEITE. F. Mortalidade por Aids no Brasil cai 38,9\% em 11 anos. O Estado de São Paulo, São Paulo, 23/09/2013. Artigo de jornal.

GARATONI, SANTI, VITA. A cura da Aids?. Revista Superinteressante, n. 159, 12/2000 Artigo de revista.

NASCIMENTO, Dilene R. A face visível da Aids. In: História, ciências, saúde: Manguinhos, v. 1. n. 1. Rio de Janeiro, 1997.

PERLONGHER, Nestor. O que é Aids. São Paulo:Brasiliense, 1987 (a).

OLIVEIRA, Lucia Helena de. A 1\% da cura. Superinteressante, n. 109, 10/1996-Artigo de revista. 
POLLAK, Michel. Os homossexuais e a AIDS. São Paulo: Estação Liberdade, 1990. . A homossexualidade masculina, ou felicidade no ghetto. In: Sexualidades Ocidentais.

Lisboa: Contexto, 1983.

REDE GLOBO. Estudos mostram que a cura da Aids está próxima. Fantástico, 14 de abr. 2013. Programa de televisão.

RIOS, Luis Felipe et al. Homossexualidade: produção cultural, cidadania e saúde. ABIA, Rio de Janeiro 2005.

ROCHA, Leonel. Sangue Contaminado. Istoé, n. 1713, São Paulo, Abril, Jul 2011.

SBT. Os filhos da Aids. Conexão Repórter, 17 mai. 2010. Programa de televisão.

SONTAG, Susan. A doença como metáfora. São Paulo: Graal, 2002.

TREVISAN, João Silvério. Devassos no paraíso: a homossexualidade no Brasil, da colônia à atualidade. Rio de Janeiro: Editora Record, 2004.

VEJA. O fator humano: pesquisa mostra que contágio da Aids em relações heterossexuais é mais difícil do que se pensava. Editorial, n. 1026, São Paulo, Abril mai. 1988.

Um excesso. Editorial, n. 871 São Paulo, abril, mai.1985.

\section{Resumo}

Este artigo trata do repertório imagético comumente associado ao HIV/Aids, que deriva diretamente do tratamento dado à doença pelos meios de comunicação nos primeiros anos da epidemia. O conteúdo ligado ao HIV/Aids, veiculado pela mídia entre 1983 e os primeiros anos da década de 1990, privilegiava quase sempre questões ligadas à morte e à morbidez. Tais escolhas temáticas estimularam a estigmatização ligada à doença, fomentando a criação de um imaginário ligado à Aids aparentemente bastante resistente às descobertas científicas e aos avanços no tratamento da doença, no qual prevalecem julgamentos de valor e conduta em detrimento das questões epidemiológicas ligadas ao HIV, marcando de forma definitiva a percepção da Aids pela população em geral.

Nossa argumentação será conduzida através da exposição de alguns exemplos de discursos ligados à Aids veiculados na mídia, assim como nas falas de pessoas das áreas médica e legal, bem como de personagens diretamente envolvidos na epidemia, além da exposição de algumas peças de prevenção à Aids veiculadas nas últimas três décadas.

\section{Palavras-chave}

HIV/Aids. Prevenção a Aids. Campanhas publicitárias. Sexualidade

\section{Abstract}

This article is about some issues related to the images that were closely associated to the vírus HIV, in the early beginning years of the epidemic, and the supposed remain of this "model" until nowadays, fostering the creation of an imaginary related to Aids and HIV, so then we can see the possible consequences of this "bond".

We will conduct the discussion through the discourses related to Aids displayed in the media, beyond the discourses from the medical authorities and juridical ones, and with the display of prevention campaigns from the last three decades. Doing that, we will try to understand the social management of the epidemics and it's reflect in the official prevention.

\section{Keywords}

HIV/Aids. Aids prevention. Advertising campaigns. Sexuality. 